\title{
Review Ph.D. Thesis: Psyco-Education Factors of Applying Visualisation in Science Education. Siauliai University, Lithuania*
}

\author{
Raffaele Pisano ${ }^{1,2}$ \\ ${ }^{1}$ Sciences, Sociétés, Cultures dans leurs Evolutions, University of Lille 1, Lille, France \\ ${ }^{2}$ Research Center for Theory and History of Science, University of West Bohemia, Plzen, Czech Republic \\ Email: pisanoraffaele@iol.it
}

Received December $23^{\text {rd }}, 2012$; revised January $26^{\text {th }}, 2013$; accepted February $8^{\text {th }}, 2013$

\begin{abstract}
This paper presents a review of a Ph.D. Thesis by Renata Bilbokaite, Natural Science Education Research Centre, Šiauliai University, Lithuania.
\end{abstract}

Keywords: History of Science and Science Education; Science and Society; Economy; I.T.

\section{On the Author}

Renata Bilbokaite, already busy with research as junior worker at the Natural Science Education Research Centre at Šiauliai University, defends her Ph.D. Thesis at the same University in November 2012: Psycho-Educational Factors of Applying Visualisation in Science Education. Language: Lithuanian/English. Research supervisor: Prof. Dr. Vincentas Lamanauskas (Šiauliai University, Lithuania). The location of the defense is the Academic Council of Education Studies of $\breve{S}$ iauliai University. The committee is composed of a distinguished and international members and opponents. Her doctoral studies involved 2009-2012 period. She prepared and published over 100 scientific articles in scientific journals, and presented over 80 works in international as well as national scientific and practical conferences, giving lectures for teachers, in the sphere of science education particularly focusing on applying visualisation in science education, management \& quality in the higher education, image of pedagogues.

\section{On the General Description and Topicality}

The thesis is organized by an Introduction and three main chapters. 1) Visualisation in science education: psycho-educational context concerning a state of art on the main objects and interactions of cognitive and socio-educational aspects; 2) Empiric psycho-educational factors of applying visualisation in science education on Epistemic-Exploratory-Diagnostic-Verification methodologies and related results; 3) Psycho-educational model of applying visualisation within science education, the nucleus of the thesis on this new modelling approach in science education studies. Passionate and interesting Discussion and Conclusions included Recommendations for different kind of readers and an international and updated list of References close the volume of this notable doctoral research under an excellent and proficient supervision. A CD-Rom is annexed, too. The results of the dissertation research are illustrated by 72

\footnotetext{
*Short review.

In the running text of this paper some quotations are cited. The pages refers her Ph.D. thesis.
}

figures and 31 tables.

The author has performed good orientation and wide educational and scientific knowledge of different parts of theory of science education considered in the thesis: epistemic analyses, analytical approach, and experimental approach included analysis of data.

The topic of thesis is contemporary and relevant in the context of up-to-date research in the sphere of science education, science and society. Particularly, a useful relevance of the Ph.D. thesis is

[...] is supposed by the complex assimilation of knowledge in Biology, Chemistry, Physics, Geography and Mathematics in comprehensive schools, which is affected by many factors, linked with conditions of the information representation within educational reality (p. 9).

The Introduction focus on the role played by the contemporary society, its transformations and technological progress related to science education and ITC.

The chapter one is mainly focused on Application of aids in lessons of past, present and future and aspects of learninggenders (9 paragraphs).

The chapter two ascribes on Attention and memory within structures of mental models' formation and related motivations within the educational contexts (7 paragraphs).

The chapter three is dedicated to study the methodology and results applied to epistemic and exploratory procedures of visualization in science education. It is composed of Discussion, Conclusions and Recommendations.

\section{On the Aims, Methods and Benefits}

The aims and methods are performed in the Introduction as well as the hypothesis and methods of the research. Thanks to the using of different fonts and structure of the text is proper and helps the reader to better orientation in the text.

One of the greatest problems within the reality of the science education is the inappropriate understanding of conceptions, phenomenon, topics and other elements of the content. Learners 
understand conceptions individually, constructing the own epistemic (p. 10).

Based on the well-declared Researches Hypotheses the main objective is psycho-educational factors of applying visualisation in science education. Particularly it "[...] is to analyse psycho-educational factors of applying visualisation during lessons of Biology, Chemistry, Physics, Geography and Mathematics in 9 - 10 forms, reasons for their heterogeneity, and the model of named factors." (p. 13). The author deeply precise the role played by theoretical and empirical sub-objectives concerning " $[\ldots]$ characteristics of visualisation within ontology of the image [...]" (p. 14), and "[...] verify results of researches with empirical substantiation of attitude of Subjects of science education - teachers and students - towards reasons, affecting the higher need for externalised visual representations and their effect on heterogeneous groups of learners under aspects of gender and form." (Ivi). On that account an original schema of research methodology (p. 17) is originally proposed by the author.

The Ph.D. thesis ascribes two main methods: theoretical and empirical-practical. A data collection for exploring opinion of populations, e.g., “[...] Philosophical and social ontological aspect of the discourse of visualisation is revealed by analysing the meaning of externalised visual representations on aspects of postmodernism, globalisation, synergetics and innovations by supplementing with ontological importance for knowledge and information societies" is proposed (p. 18). The empirical-practical method mainly concerns "[...] benefits of applying visualisation in science education on psycho-educational aspect were gained during the empirically based theoretical discourse analysis" (p. 19).

From a methodological and pedagogical-scientific point of view I am also mostly appreciative of the clarity and precision of the exposition constantly paid attention both contents and understanding both for specialists and scientific and management readers, both Lithuanian and Western European scholars.

\section{On the Results and Author's Recommendations}

The results and modelling presented by the author are crucial and the overall technical intensity of the thesis is significant and typically for a very much qualified Ph.D. thesis: Identifications of factors, Exploratory research, Diagnostic research, Verification of results (Chapter 2, Section 2.2). "The Ph.D. thesis research results and the constructed model application of concrete aids of visualisation should be verified during lessons by forming questions if the similar positive factors exist in different classes, groups of students with different skills as well as on heterogonous aspects of gender, learning needs, educational environments and activities." (p. 32). Thus the results are very original and certainly considerable such as important classes of science education, history and science education items within an international panorama. In fact some modelling and outlines are already published in highly reputable conferences and journals in science education and management \& quality.

Particularly, the Ph.D. thesis ascribes two main results: conclusion within theoretical context and conclusions within empirical-practical context.

When it come the former, according to the author visualisation is indivisible from the image ontogenesis "[...] within the context of the psychological discourse, application of visualisation could affect the management (stimulations) of cognitive processes of the Subject-together with the artefact of external multimodal and multidimensional externalised representations" (pp. 33-34).

When it come the empirical-practical context: "[...] students in 9 - 10 forms experience learning difficulties in subjects of science education due to limitedness of activity of cognitive processes (perception, attention, memory and imagination)" [... and .... attitude of teachers experts, it is identified that in disciplines of science education, classical visualisation methods and ways, presenting educational information, dominate, the usage of which during the last five years had a tendency to decrease and as it is planned-it is about to decrease in future" (p. 35).

The author close her results with a list of recommendations for different kind of readers: authors of manuals, software, managers of publishing houses, scientists and teachers (pp. 38-39 and correlated pages).

\section{Conclusion}

The structure of thesis conforms to principles and requests to the structure of a scientific Ph.D. thesis. The author studied and used appropriate number of international references sources used and cited in the thesis. It is the largely evidence of the deep theoretical knowledge and extremely good orientation in the problem discussed in science education. The word processing of the thesis appears also adequate. The using of different fonts and structure of the text is proper and helps the reader to better orientation in the text. Thus the Ph.D. thesis is well written and swell organized, with a suitable Introduction to interesting contents-chapters and through international references to cited works.

In my opinion, the author produced an urgent-emergency and a significant research and contribution of support for both science education readings, scientist-pedagogists and historians of science and natural science specialists.

The thesis by Renata Bilbokaite performed all the conditions for gaining the $\mathrm{PhD}$. degree in Science Education. The volume composition makes for absorbing reading. 